\section{AN OUTBREAK OF SEVERE ACUTE RESPIRATORY SYNDROME IN A NURSING HOME}

To the Editor: Over a period of 4 months, the severe acute respiratory distress syndrome (SARS) infected 1,755 persons, resulting in 298 deaths in Hong Kong. ${ }^{1}$ Nursing homes are particularly vulnerable to cross-infection as a result of the crowded living environment, inadequate ventilation, substandard hygiene, and lack of qualified nursing staff. Recognition of clinical features at an earlier stage of the infection and stringent isolation procedures could prevent outbreaks in institutions, but the presentation of SARS may be less florid in older people. ${ }^{2}$ Nursing home residents, because of their frailty and comorbidities, are frequent users of hospital services, including emergency rooms (ERs) and acute wards, thus increasing their risk of exposure to infectious agents in hospitals. Demented or extremely frail patients may pose particular risk to other persons, because they may not be able to communicate and are only recognized after those who have come into contact with them fall ill. Also, cognitively impaired older patients may have difficulty keeping their facemasks on and sometimes exhibit high-risk behavior such as spitting. We report a cluster of seven cases (Table 1) illustrating the spread of SARS from a hospital to the community and, in particular, a nursing home. All the cases were diagnosed clinically ${ }^{3}$ and had positive viral isolates or serological tests to coronavirus.

The nursing home involved was typical of many privately run institutions of its type. Located in an old

Table 1. A Cluster of Cases with Confirmed Severe Acute Respiratory Syndrome at a Nursing Home (NH) in April 2003

Status in Nursing Home

\begin{tabular}{|c|c|c|c|c|c|c|c|}
\hline \multirow{2}{*}{$\begin{array}{l}\text { Case } \\
\text { Number }\end{array}$} & \multirow[b]{2}{*}{ Sex/Age } & \multicolumn{3}{|c|}{ Status in Nursing Home } & \multirow{2}{*}{$\begin{array}{l}\text { Date of Onset } \\
\text { of Illness }\end{array}$} & \multirow{2}{*}{$\begin{array}{l}\text { Probable Mode } \\
\text { of Transmission }\end{array}$} & \multirow[b]{2}{*}{ Outcome } \\
\hline & & Resident & Employee & Visitor & & & \\
\hline 1 & Female/87 & $\sqrt{ }$ & & & April 12 & $\begin{array}{l}\text { Likely to have been infected by } \\
\text { a nurse during a recent } \\
\text { admission (April } 4 \text { to } 8 \text { ), when } \\
\text { there was an outbreak on the } \\
\text { ward. }\end{array}$ & Recovered \\
\hline 2 & Female/81 & $\sqrt{ }$ & & & April 13 & $\begin{array}{l}\text { Exposed to Case } 1 \text { in } \mathrm{NH} \\
\text { between April } 8 \text { and } 12 .\end{array}$ & Died on Day 13 \\
\hline 3 & Female/65 & & $\sqrt{ }$ & & April 15 & $\begin{array}{l}\text { Exposed to Case } 1 \text { in } \mathrm{NH} \\
\text { between April } 8 \text { and } 12 .\end{array}$ & Died on Day 37 \\
\hline 4 & Male/28 & & & $\sqrt{ }$ & April 15 & $\begin{array}{l}\text { Case 1's grandson. Exposed } \\
\text { to Case } 1 \text { while visiting her at } \\
\mathrm{NH} \text { between April } 8 \text { and } 12 \text {. }\end{array}$ & Recovered \\
\hline 5 & Male/27 & & & $\sqrt{ }$ & April 18 & $\begin{array}{l}\text { Another grandson of Case 1, } \\
\text { and Case } 4 \text { 's younger brother. } \\
\text { Exposed to Case } 4 \text { and } \\
\text { possibly Case } 6 \text { via household } \\
\text { contact. }\end{array}$ & Recovered \\
\hline 6 & Male/88 & & & $\sqrt{ }$ & April 19 & $\begin{array}{l}\text { Case 1's husband. Exposed to } \\
\text { Case } 1 \text { while visiting her at } \mathrm{NH} \\
\text { between April } 8 \text { and } 12 \text {. Also } \\
\text { lived with Cases } 4 \text { and } 5 \text {. }\end{array}$ & Recovered \\
\hline 7 & Female/93 & $\sqrt{ }$ & & & April 25 & $\begin{array}{l}\text { Admitted to a "fever" ward with } \\
\text { fever and clinical features of } \\
\text { heart failure on April } 16 . \\
\text { Initially improved with diuretics } \\
\text { and antibiotics. Developed } \\
\text { fever again on Day } 9 \text {, } \\
\text { subsequently confirmed to } \\
\text { have SARS, probably } \\
\text { acquired on "fever" ward. }\end{array}$ & Died on Day 20 \\
\hline
\end{tabular}


building, it was crowded, with an average living space of $6 \mathrm{~m}^{2}$ per resident. Individual beds were separated with wooden boards approximately $1.2 \mathrm{~m}$ high. The small communal toilet and shower area was near the living and dining area. Frailer residents usually used bedside urinals or commodes for toileting. No single room was available for isolation purposes. The staff-to-resident ratio was around $1: 15$, and the majority of carers had no formal training in health care.

This report illustrates how a single nursing home resident infected with SARS during hospitalization gave rise to several secondary cases, some resulting in death. During the SARS epidemic, nursing homes residents admitted to some acute hospitals with fever, but clinically not suspected to be suffering from SARS, would be transferred from a "fever" ward to a "cohorting" ward for about 10 days before returning to their nursing homes. Although such measures may have reduced the spread of the infection to nursing homes, they have, nevertheless, increased the workload of acute hospitals tremendously, and in some unfortunate instances, led to further in-hospital outbreaks. Community-based outreach teams including geriatricians and nurses were mobilized to closely monitor nursing home residents discharged from hospitals. They worked closely with the department of health and hospital wards to keep up-to-date information on nursing home residents afflicted with SARS. Advice was given to nursing home staff on the use of protective gear and provision of isolation facilities for residents with febrile illness and those recently discharged from hospitals to prevent cross-infection. Perhaps the way to manage this in the future is to keep nursing home residents onsite wherever possible, avoiding the need to come into contact with high-risk areas such as the ER and hospital wards.

Wency W. Ho, MRCP Elsie Hui, FRCP Timothy C. Kwok, FRCP Jean Woo, FRCP Department of Medicine and Therapeutics The Chinese University of Hong Kong Shatin, New Territories, Hong Kong

Nancy W. Leung, FRCP Department of Medicine The Alice Ho Min Ling Nethersole Hospital Tai Po, New Territories, Hong Kong

\section{REFERENCES}

1. Department of Health Hong Kong Special Administrative Region. SARS Web site [On-line]. Available: www.info.gov.hk/info/sars/eindex.htm, Accessed July 16, 2003.

2. The Hong Kong Geriatric Society's Position Statement on SARS in Elders [Online]. Available. www.fmshk.com.hk/hkgs/sars/HKGS-Position-SARS.pdf, Accessed July 16, 2003.
3. Case definitions for surveillance of acute severe respiratory syndrome (SARS). Geneva: World Health Organization, 2003. Available: www.who.int/csr/sars/ casedefinition/en, Accessed July 16, 2003.

\section{SEVERE ACUTE RESPIRATORY SYNDROME: EFFECT ON COMMUNITY AND RESIDENTIAL AGED CARE SERVICES IN SINGAPORE}

To the Editor: From March 2003 to May 2003, 206 cases of probable severe acute respiratory syndrome (SARS) were identified in Singapore. Recognition of the highly infectious nature of SARS led to the early imposition of strict infection-control measures for all healthcare establishments. This included mandatory use of personal protection equipment ((PPE); N95 mask, gown, goggles, and gloves) for all healthcare workers who had contact with patients, restriction of visitors to healthcare facilities, and the restriction of movement of healthcare workers between institutions. These measures were coupled with a concerted effort by the government to regularly update the public and to encourage citizens to take personal responsibility for their health. ${ }^{1}$ The overall strategy was one of deliberate and decisive coordination, communication, and collaboration, which resulted in Singapore being removed from the World Health Organization list of areas with local SARS transmission on May 31, 2003. ${ }^{2}$

Early local experience revealed that older patients with multiple comorbidities may present atypically, resulting in delayed diagnoses and consequent spread of the disease. This led to the inference that all older persons with multiple comorbidities and a history of recent contact with healthcare institutions were potentially infectious. Consequently, the preventive measures applied to hospitals were extended to all community and residential care facilities for the elderly. Until recently, this meant that healthcare workers were required to wear full PPE whenever they were to have any contact with older patients, regardless of the setting in which such contact took place.

Within the community, clients were required to have their temperatures screened before each visit to their daycare facilities. Additionally, fully gowned and masked healthcare workers had to escort clients who required transport assistance. Understandably, such spectacles can be unnerving and have led to anecdotal reports of stigmatization and isolation of these clients. Within nursing homes, the use of PPE deprived residents of the scant comfort they find in recognizing the familiar faces of their carers and led to confusion and fear, especially in residents with dementia. Restrictions on visitations have also deprived residents of the warmth derived from interacting with their loved ones, thus further exacerbating the situation. Restrictions on movements and the requirements for PPE also resulted in fewer outings for nursing home residents, further constricting their opportunity for interaction with the community at large. Although the effect of these measures has not been assessed quantitatively, it may not be unreasonable to assume that the quality of life of older persons using community and residential care facilities has been adversely affected.

Other measures that have been introduced include the requirement for regular surveillance for clusters of febrile 
patients within nursing homes and the linkage of community hospitals and nursing homes to specific acute hospitals so as to limit unnecessary and excessive movement of patients between institutions. The former strategy allows for early detection of a possible resurgence of SARS, whereas the latter has the twofold effect of limiting the risk of disease transmission in the event of a resurgence and eases the process of contact tracing should a case be found. ${ }^{3}$

The preventive measures against SARS that have been put in place within community services and nursing homes in Singapore may appear excessive to detractors, but the unforgiving nature of the disease, its high fatality rate in the elderly, ${ }^{4}$ and the expectation of a seasonal resurgence of this condition $^{5-7}$ provide sufficient justification for continued vigilance.

Reassurance may be drawn from the willingness of the government to continually and openly review the situational risks and to adjust the precautions required. ${ }^{8} \mathrm{~A}$ recent review of patients previously classified as "suspect" cases, as well as close to 10,000 patients who had exposure to SARS during the outbreak, led to the reclassification of 32 "suspect" cases as "probable SARS" but also excluded any possible cases that may have been missed from among the larger cohort. Since July 21, 2003, the requirement for full PPE during routine contact with afebrile patients from community health services and nursing homes has been lifted. This brings a welcomed reprieve to healthcare workers and patients alike and may portend the resumption of some of the social activities that had been curtailed because of SARS.

While the fraternity of elderly care providers strives to establish a new equilibrium that incorporates the needs of the frail elderly and the requirement for constant vigilance it is hoped that the retention of the other measures that have been mentioned will help to ensure the early detection of future resurgences of SARS or other similar conditions.

Yih Y. Sitoh, MRCP, FAMS Department of Geriatric Medicine Tan Tock Seng Hospital Singapore

\section{REFERENCES}

1. Long S. Singapore at war. The Straits Times May 13, 2003.

2. World Health Organization. Update 70 - Singapore removed from list of areas with local SARS transmission [On-line]. Available: www.who.int/csr/don/ 2003-05-30a/en, Accessed May 31, 2003.

3. Ministry of Health press release: SARS - continued vigilance [On-line]. Available: http://app.moh.gov.sg/new/new02.asp? $i d=1$ omid=7580, Accessed July 1, 2003.

4. World Health Organization Communicable Disease Surveillance and Response. Severe acute respiratory syndrome (SARS): Status of the outbreak and lessons for the immediate future. Geneva: World Health Organization, 2003.

5. Fleck F. WHO says SARS outbreak is over, but fight should go on. BMJ 2003;237:70.

6. World Health Organization. Update 89 - What happens if SARS returns? [Online]. Available: www.who.int/csr/don/2003-06-26/en/print.html, Accessed July 4, 2003.

7. World Health Organization. Update 94-Preparing for the next influenza season in a world altered by SARS [On-line]. Available: www.who.int/csr/don/ 2003-07-03/en/print.html, Accessed July 4, 2003.

8. Khalik S. Hospitals to lift restrictions; last patient out of SARS ward. The Straits Times July 17, 2003.

\section{USE OF CONSERVATIVE SURGERY FOR STAGE I BREAST CANCER FALLS DRAMATICALLY FOR WOMEN AGED 80 AND OLDER}

To the Editor: Breast cancer in Switzerland is particularly prevalent, and the Swiss canton of Geneva has one of the highest incidence rates in Europe. ${ }^{1}$ As in other industrialized countries, the risk of breast cancer increases with age, and more than one-fourth of cases occur after the age of 70 . Despite the growing number of elderly cancer patients, treatment recommendations for the elderly often remain inconsistent and quite different from those given to their younger counterparts. ${ }^{2-4}$ As a consequence, elderly patients with breast cancer often do not receive standard treatments in daily practice.

We examined the type of surgical treatment given to women with Stage I breast cancer according to age. The study included all women with pathologically proven primary Stage I breast cancer (size $\leq 2 \mathrm{~cm}$ with no lymph node invasion) recorded at the Geneva cancer registry between 1995 and 1999. Patients with bilateral breast cancer were excluded. For all women aged 80 and older, additional data on health status, comorbid conditions, and patients/family treatment refusal were extracted from clinical files.

Of the 511 women with Stage I breast cancer, 402 $(79 \%)$ underwent breast-conserving surgery plus radiotherapy, $57(11 \%)$ had mastectomy, $27(5 \%)$ had breastconserving surgery alone, $13(2 \%)$ received no surgical treatment, and $12(2 \%)$ had bilateral mastectomy. Surgical treatments were similar up to the age of 79 but changed dramatically after age 80 (Figure 1). In this age group $(\mathrm{n}=28)$, only $11(39 \%)$ women underwent breast-conserving surgery, eight $(29 \%)$ had no surgical treatment, and five $(18 \%)$ had bilateral mastectomy. No oncological reasons were found for bilateral mastectomy, and all were performed for static/cosmetic thoracic symmetry. Of the eight women who did not have surgery, three had serious comorbid conditions, three had compensated comorbid conditions, and two refused surgery. Six of the eight women who did not have surgery received tamoxifen only, and two had no treatment at all.

Breast cancer in the elderly is a public health concern. Surgical management of early breast cancer after the age of

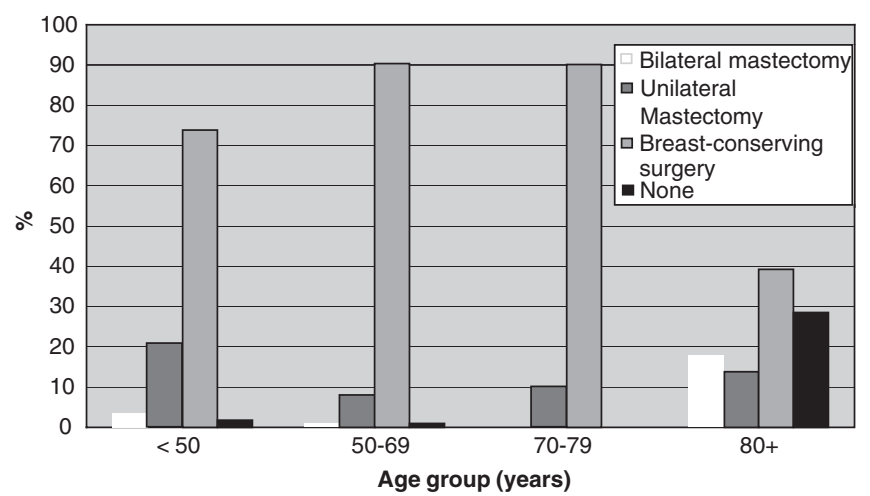

Figure 1. Surgical treatment of women with Stage I breast cancer by age group 
79 differs considerably from that of younger women. Breast-conserving surgery is underused, whereas mastectomy, particularly bilateral mastectomy, is frequently performed. The shorter life expectancy and the presence of comorbid conditions certainly influence the surgical therapeutic choice, but unclear standards, preconceived ideas, or the physician's/patient's preferences also seem to influence it. Individualized treatment is often appropriate in geriatric oncology, but a broader standardization is recommended. This would have the following benefits in elderly patients: assuring effective therapy in accordance with comorbidities, promoting breast conservation if desired, and reducing unnecessarily mutilating surgery, including bilateral mastectomies, to a minimum.

Elisabetta Rapiti, MD Gérald Fioretta, BSc Isabelle Neyroud-Caspar, MD Christine Bouchardy, MD, PhD Geneva Cancer Registry Institute for Social and Preventive Medicine University of Geneva Geneva, Switzerland

Georges Vlastos, $M D$ Peter Schäfer, MD Department of Gynecology and Obstetrics André-Pascal Sappino, MD Division of Oncology John Kurtz, MD Division of Radio-Oncology Geneva University Hospitals Geneva, Switzerland

\section{REFERENCES}

1. Bouchardy C. In: Parkin DM, Whelan SL, Ferlay J et al., eds. Cancer Incidence in Five Continents Volume VII. IARC Scientific Publications No. 143. Lyon: International Agency for Research on Cancer, 1997, pp. 666-669.

2. Goldhirsch A, Glick JH, Gelber RD et al. Meeting highlights. International consensus panel on the treatment of primary breast cancer. J Natl Cancer Inst 1998;90:1601-1608.

3. Yancik R. Cancer burden in the aged. An epidemiologic and demographic overview. Cancer 1997;80:1273-1283.

4. Balducci L, Phillips DM. Breast cancer in older women. Am Fam Physician 1998;58:1163-1172.

\section{A PREDICTIVE MODEL OF IN-HOSPITAL MORTALITY IN ELDERLY PATIENTS ADMITTED TO MEDICAL INTENSIVE CARE UNITS}

To the Editor: The risk stratification of patients in medical intensive care units (MICUs) is still mainly based upon the use of several acute physiopathological scales. In a recent study, ${ }^{1}$ the authors found that the prognosis of elderly patients hospitalized in a MICU (659 patients aged $\geq 65$ ) depended not only upon the Acute Physiology and Chronic Health Evaluation (APACHE II) score, ${ }^{2}$ but also upon a series of preexisting conditions, such as loss of functional independence measured using the activities of daily living scale $(A D L \geq 1)$, moderate to severe cognitive impairment evaluated using the Short Portable Mental
Status Questionnaire (SPMSQ $\geq 4$ ), and low body mass index (BMI).

This finding prompted the authors to evaluate whether the inclusion of these few specific prognostic indicators into a mathematical predictive model might add to the accuracy of the estimate of the individual risk of in-hospital mortality as it is currently evaluated in MICUs through the use of acute physiopathological scales.

To estimate the individual probability of in-hospital mortality, an equation was developed, introducing the constant derived from the logistic regression and the variables independently predictive of mortality (lack of independence, $\mathrm{ADL} \geq 1$; moderate to severe cognitive impairment, $\mathrm{SPMSQ} \geq 4$; APACHE score; $\mathrm{BMI}$ ), multiplied by one's own $\beta$ (regression coefficient), according to the formula:

$R=\mathrm{e}^{\mathrm{x}} /\left(1+\mathrm{e}^{\mathrm{x}}\right) \mathrm{X}=$ constant $+(\text { variable } \times \alpha)_{\mathrm{n}}$

Receiver operating characteristic (ROC) curves $^{3}$ (a graphic display of sensitivity plotted against 1 - specificity for all possible selection of decision thresholds that can be used to predict survival) were subsequently elaborated on the basis of the individual probability of inhospital death computed by each of two models: APACHE II original equation corrected for diagnostic categories $^{2}$ and model including the independent predictors identified.

The discriminant power of each model was evaluated by comparing areas under the ROC curve using the $Z$ test statistic. $^{3}$

Among the 659 patients enrolled were 352 men $($ mean age \pm standard deviation $=75.0 \pm 7.0)$ and 307 women (mean age $=78.4 \pm 7.7$ ). Ninety-seven deaths $(14.7 \%)$ occurred.

The mortality risk computed using the original APACHE II equation, corrected for diagnostic categories, ${ }^{2}$ was $16.6 \%$.

The mortality risk estimated using the model, including BMI, ADL, SPMSQ, and APACHE II score, according to the equation

$$
\begin{aligned}
R= & \mathrm{e}^{\mathrm{x}} /\left(1+\mathrm{e}^{\mathrm{x}}\right) \\
\mathrm{X}= & -2,2004+(-0.0625 \times \mathrm{BMI}) \\
& +(0.0699 \times \mathrm{APACHE} \text { II }) \\
& +(1.0462 \text { if ADL } \geq 1 \text { function lost }) \\
& +(1.3827 \text { if SPMSQ } \geq 4 \text { errors })
\end{aligned}
$$

was $14.73 \%$.

Figure 1(A) shows the ROC curve for the two models; the area under the curve (AUC) is 0.691 (95\% confidence interval $(\mathrm{CI})=0.63-0.75)$. Figure $1(\mathrm{~B})$ displays the ROC curve for the model including BMI, ADL, SPMSQ, and APACHE II score; the AUC is 0.798 (95\% CI $=0.75-0.85)$.

The discriminative power of this latter model was significantly better than that of the APACHE II corrected for diagnostic categories $(\mathrm{Z}=3.65, P<.001)$.

The authors recently reported that cognitive, functional, and nutritional measures have prognostic relevance for hospital mortality in elderly patients admitted to the MICU. ${ }^{1}$ The results of the present study suggest that the inclusion of these few specific prognostic indicators into a 

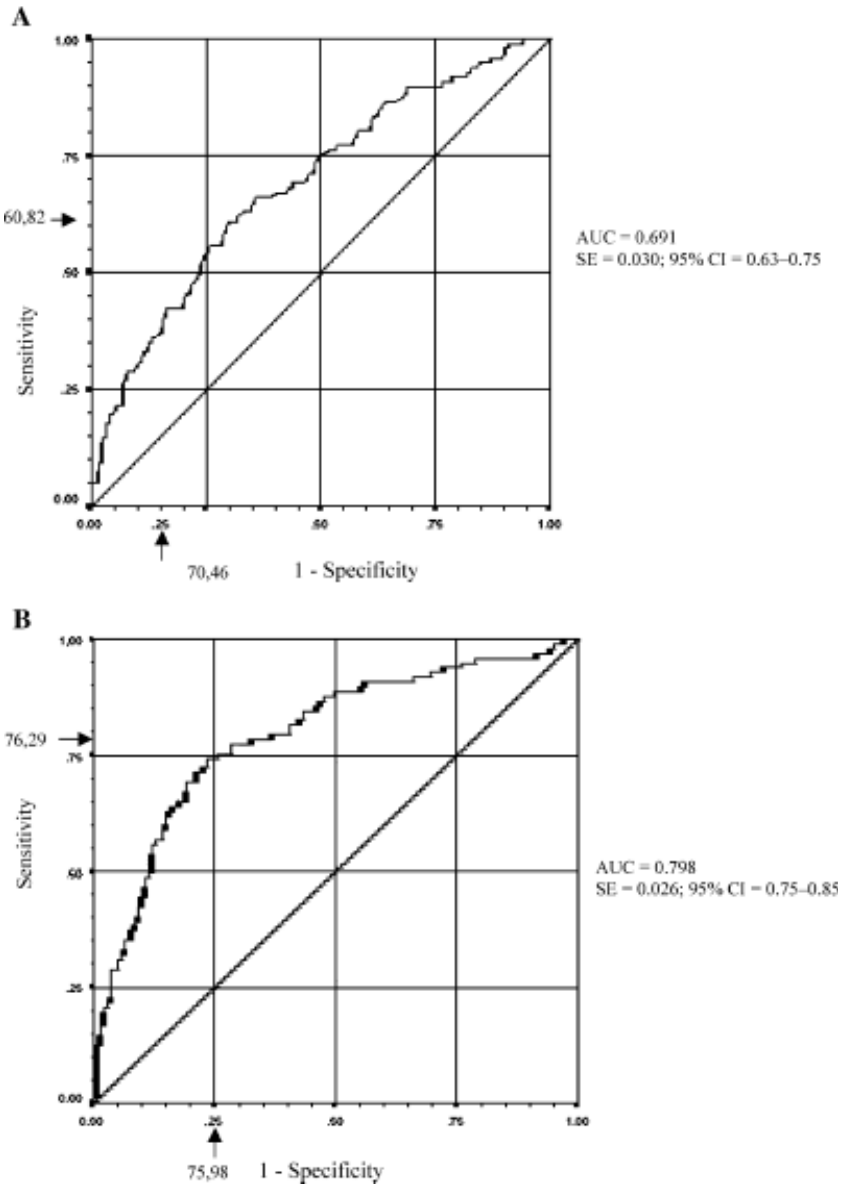

Figure 1. Receiver operating characteristic curves for the original Acute Physiology and Chronic Health Evaluation (APACHE II) model (1A) and for the model including body mass index, activities of daily living, Short Portable Mental Status Questionnaire, and Acute Physiology and Chronic Health Evaluation score (1B). AUC = area under the curve; $\mathrm{SE}=$ standard error; $\mathrm{CI}=$ confidence interval.

mathematical model provides a reliable estimate of the individual risk of in-hospital mortality. These results reinforce current evidence on predictors of mortality in elderly hospitalized patients. ${ }^{4-6}$

MICUs are costly, and these often-crowded hospital units are where elderly patients usually experience prolonged immobilization for instrumental monitoring and intensive life support. The improved prediction of inhospital mortality beyond that achieved with currently available mathematical models, such as the APACHE II, should allow for reserving this high-cost approach to those clinical patients who are more likely to benefit. Beyond these clinical and economical advantages, the knowledge of these predictors and the adoption of this model might also be useful to researchers who study the effectiveness of clinical interventions on the risk of mortality in this setting.

In conclusion, the in-hospital prognosis of elderly patients admitted to a MICU depends not only upon acute physiopathological impairment but also upon other conditions, such as loss of functional independence, moderate to severe cognitive impairment, and a low BMI.
The inclusion of these few variables into a mathematical model provides a better estimate of the individual risk of mortality than that achieved using only acute physiopathological model.

Mario Bo, $M D$

Silvio Raspo, $M D$

Massimiliano Massaia, MD

Paola Cena, MD

Francesca Bosco, MD

Fabrizio Fabris, MD, FP

Department of Medical and Surgical Science

Section of Gerontology

University of Turin

Turin, Italy

Camillo Antro, $M D$

Valerio Gai, MD, AP

Medical Intensive Care Unit

Turin, Italy

\section{REFERENCES}

1. Bo M, Massaia M, Raspo S et al. Predictive factors of in-hospital mortality in elderly patients admitted to a medical intensive care unit. J Am Geriatr Soc 2003;51:529-533.

2. Knaus WA, Draper EA, Wagner D et al. APACHE II. A severity of disease classification system. Crit Care Med 1985;13:818-829.

3. Hanley JA, McNeil BJ. A method of comparing the areas under receiver operating characteristic curves derived from the same cases. Radiology 1983;148:839-843.

4. Teno JM, Harrell FE, Knaus W et al. Prediction of survival model for older hospitalized patients: The HELP survival model. J Am Geriatr Soc 2000;48:S16-S24.

5. Chelluri L, Pinsky MR, Donahoe MP et al. Long-term outcomes of critically ill elderly patients requiring intensive care. JAMA 1993;269:3119-3123.

6. Incalzi RA, Capparella O, Gemma A et al. The interaction between age and comorbidity contributes to predicting the mortality of geriatric patients in the acute-care hospital. J Intern Med 1997;242:291-298.

\section{BREAST HEMATOMA DUE TO AN AXILLARY PAD IN AN ANTICOAGULATED PATIENT}

To the Editor: A 78-year-old woman with diabetes mellitus and hypertension was admitted to the acute care geriatric ward of our medical center for rapid swelling of the left breast. Three months earlier, she had undergone hip replacement complicated by a femoral venous thrombosis of the same leg. She was receiving enalapril $20 \mathrm{mg} / \mathrm{d}$, chlorthalidone $25 \mathrm{mg} / \mathrm{d}$, glibenclamide one tablet three times a day, and enoxaparin $4000 \mathrm{IU} / \mathrm{d}$. The patient was independent in activities of daily living but, because of residual postural instability, could walk only with the help of a walker.

At physical examination, the breast was swollen, warm, and tender. A prominence with a central depression was evident in the axillary region. Hemoglobin level was $8.7 \mathrm{~g} / \mathrm{dL}$ (it had been $12.1 \mathrm{~g} / \mathrm{dL} 2$ months before) but platelet count, activated partial thromboplastin, and prothrombin time were within normal limits. Ultrasonography showed a 


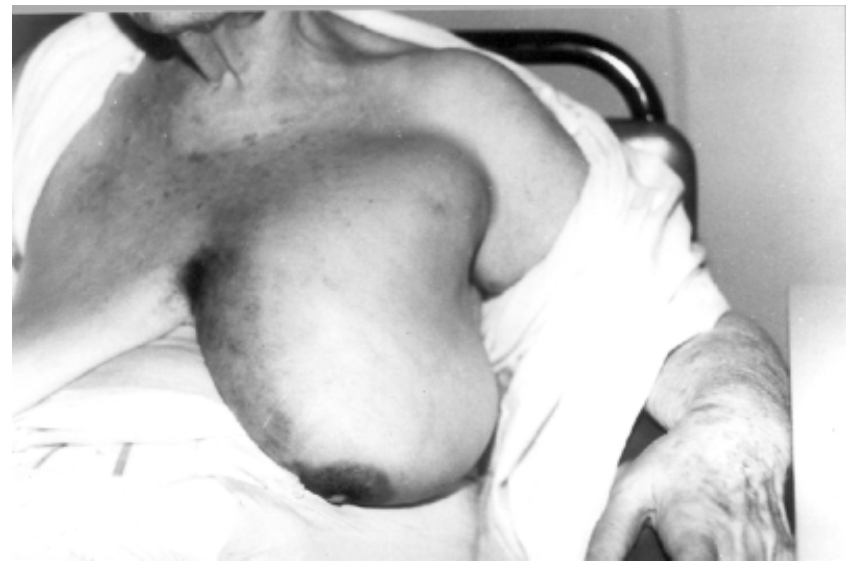

Figure 1. The left breast was swollen and showed a prominence with a central depression in the axillary region. A purple-blue discoloration was evident in the depending regions of the breast.

diffusely hypoechoic mammary gland, and a tentative diagnosis of breast hematoma was made. The onset of a purple-blue discoloration of the depending regions of the breast 12 hours after admission later confirmed this (Figure 1). It is likely that the repeated microtrauma caused by the pad of the walker on the axillary lobule of the breast, corresponding to the observed skin depression, caused the hemorrhage.

The combination of an expanding and aging population and a sharp increase in the indications for orthopedic surgery will bring about a dramatic increase in the use of rehabilitation devices, but it is likely that the prevalence of medical problems requiring anticoagulation will also increase, as well as conditions, such as polypharmacy and comorbidity, that are associated with an increased risk of bleeding in these individuals. ${ }^{1-3}$

The use of devices causing elevated skin pressure should be prescribed appropriately, and in any instance, pressure points should be systematically inspected to detect any sign of bleeding in patients receiving anticoagulants. Finally, even low-dose fractionated heparin should be considered a potential threat in frail, older subjects.

Giovanni Gambassi, $M D$ Raffaele Antonelli Incalzi, MD Centro di Medicina dell'Invecchiamento Università Cattolica del Sacro Cuore Rome, Italy

\section{REFERENCES}

1. Landefeld CS, Goldman L. Major bleeding in outpatients treated with warfarin. Incidence and prediction by factors known at the start of outpatient therapy. Am J Med 1989;87:144-152.

2. Fhin SD, Callahan CM, Martin DC et al. The risk for and severity of bleeding complications in elderly patients treated with warfarin. The National Consortium of Anticoagulation Clinics. Ann Intern Med 1996;124:970-979.

3. Ezekowitz MD, Levitte JA. Preventing stroke in patients with atrial fibrillation. JAMA 1999;281:1830-1835.

\section{BENEFITS OF STATINS IN THE ELDERLY}

To the Editor: A case-controlled study of newly admitted nursing home residents aged 65 and older ${ }^{1}$ found a $31 \%$ reduction in 1-year mortality and a trend toward fewer hospital admissions and maintenance of physical function in statin (3-hydroxy-3methyl-glutaryl coenzyme A reductase inhibitor) users. Although the authors of the study focused on the prevention of cardiovascular events associated with statin use to explain their findings, they failed to mention other possible clinical benefits from statins, particularly in long-term use, that may have affected their positive outcomes.

There is now an emerging body of evidence suggesting that the beneficial effects of statins extend beyond the prevention of cardiovascular and cerebrovascular events. Several observational and case-controlled studies have shown positive protective effects in the areas of osteoporosis and dementia. One study ${ }^{2}$ first described an increase in bone mineral density in mice treated with a statin, and similar increases have been found in at least two casecontrolled studies in postmenopausal women. ${ }^{3,4}$ In the largest of the observational studies published, the investigators analyzed data on more than 91,000 elderly people from the UK General Practice Research Database and found that statin users had a $45 \%$ lower risk of all types of fracture and an $88 \%$ reduction in hip fracture risk. ${ }^{5}$

There have also been a number of promising results from studies showing lower rates of Alzheimer's disease (AD) in statin users. ${ }^{6-8}$ In a nested case-controlled study of 1,300 people, again from the UK General Practice Research Database, it was found that the relative risk of dementia for those prescribed statins was $0.29 .^{6}$ A similar highly significant result was found in another study, ${ }^{7}$ which performed a large cross-sectional observational investigation using the databases at three U.S. hospitals and found a $60 \%$ to $73 \%$ lower prevalence of $\mathrm{AD}$ in the cohort taking statins.

Although observational in design and subject to various biases and confounding factors, the results of these studies need to be considered when research of statin use in the elderly is undertaken. ${ }^{1}$ These findings also offer a stimulating potential for the development of new therapeutic approaches to two of the most common and debilitating diseases in geriatric clinical practice. Exploring this potential is required by means of rigorously designed randomized controlled trials.

Henry Zeimer, MB.BS, FRACP Austin and Repatriation Medical Center Aged Care Services Heidelberg 3081

Victoria, Australia

\section{REFERENCES}

1. Eaton CB, Lapane KL, Murphy JB et al. Effect of statin (HMG-Co-A-Reductase Inhibitor) use on 1-year mortality and hospitalization rates in older patients with cardiovascular disease living in nursing homes. J Am Geriatr Soc 2002;50:1389-1395.

2. Mundy GR, Garrett R, Harris S et al. Stimulation of bone formation in vitro and in rodents by statins. Science 1999;286:1946-1949.

3. Edwards CJ, Hart DJ, Spector TD. Oral statins and increased bone mineral density in post menopausal women. Lancet 2000;355:2218-2219. 
4. Pasco JA, Kotowicz MA, Henry MJ et al. Statin use, bone mineral density and fracture risk. Arch Intern Med 2002;162:537-540.

5. Meier CR, Schlienger RG, Kraenzlin ME et al. HMG-CoA reductase inhibitors and the risk of fractures. JAMA 2000;283:3205-3210.

6. Jick H, Zornberg GL, Jick SS et al. Statins and the risk of dementia. Lancet 2000;356:1627-1631.

7. Wolozin B, Kellman W, Ruosseau P et al. Decreased prevalence of Alzheimer disease associated with 3-hydroxy-3-methyglutaryl coenzyme A reductase inhibitors. Arch Neurol 2000;57:1439-1443.

8. Rockwood K, Kirkland S, Hogan DB et al. Use of lipid-lowering agents, indication bias, and the risk of dementia in community-dwelling elderly people. Arch Neurol 2002;59:223-227.

\section{CHOLESTEROL AND OSTEOPOROSIS IN} POSTMENOPAUSAL WOMEN: A PILOT STUDY

To the Editor: Osteoporosis is a major public health problem in the aging population. It is the main cause of bone fractures in postmenopausal women and the elderly, causing deformity, pain, and loss of independence. It is the most common type of metabolic bone disease, affecting one in four women and one in eight men aged 50 and older.

Thirty percent of postmenopausal women sustain an osteoporotic fracture during their lifetime. Because of the exponential increase in fracture incidence after age 75 , even interventions that slightly reduce rate of bone loss (from $1.0 \%$ to $0.5 \%$ per year, for example) are capable of greatly reducing fracture risk. In view of the increase in the aging population and the resultant rise in the prevalence of osteoporosis, the need for focused preventive strategies should become a major public health priority.

One study showed that plasma leptin levels but not percentage fat were associated with bone mineral density (BMD) and the presence of vertebral fractures in postmenopausal women. ${ }^{1}$ Another study pointed out that lowdensity and high-density lipoprotein cholesterol were inversely and positively correlated with vertebral fractures in postmenopausal women. ${ }^{2}$ Studies have shown that inhibitors of 3-hydroxy-3-methylglutaril coenzyme A (statins) increase BMD by blocking the cholesterol biosynthetic pathway. Researchers have also shown that lipid-lowering agents such as statins increase BMD and reduce fracture rate, ${ }^{3-5}$ but this is not a consistent finding, with some studies showing no benefit from statins. ${ }^{6}$ It was reported in a recent study that diabetic men using statins have higher bone density than diabetic men not requiring this therapy, but no significant effect was found in diabetic women. ${ }^{7}$ In the study of the effect of pravastatin on frequency of fractures, fracture prevention was not shown. ${ }^{8}$ Aminobisphosphonates, which are used in the treatment of osteoporosis, are potent antiresorptive agents that cause osteoclast apoptosis, which they achieve by inhibiting the farnesyl diphosphate synthase enzyme in the mevalonate pathway, which is also involved in the synthesis of cholesterol. ${ }^{9}$ Statins decrease cholesterol synthesis by inhibiting the first step in the same biochemical pathway affected by aminobisphosphonates, and this is their currently proposed mode of action on the bone. Recent research also suggests that statin users have a $60 \%$ reduction in fracture risk, which is greater than what
Table 1. Bone Mineral Density Levels in Patients with High and Normal Cholesterol Levels

\begin{tabular}{cc} 
Osteopenia/ Normal Bone \\
Osteoporosis & Mineral \\
at Hip or & Density at \\
Spine & Hip or Spine \\
\hline
\end{tabular}

Cholesterol Level $\mathrm{n}(\%)$

High cholesterol
$(>5.2 \mathrm{mmol} / \mathrm{L} ;>200 \mathrm{mg} / \mathrm{dL})$
Normal cholesterol
$(<5.2 \mathrm{mmol} / \mathrm{L} ;<200 \mathrm{mg} / \mathrm{dL})$

$23(59)$

$1(33)$

$16(41)$

would be expected from increased BMD alone. ${ }^{10}$ It is not clear at this point whether high cholesterol is contributing to the cause of osteoporosis. Our hypothesis is that elevated cholesterol is associated with the pathogenesis of osteoporosis on a vascular basis similar to that of atherosclerosis.

The objective of this study was to determine the association between serum cholesterol levels and osteopenia/osteoporosis. We used retrospective chart review of 42 consecutive subjects seen in an endocrinology clinic at the University of Alberta. Using a standardized data collection form, demographic information, details about BMD and severity of osteoporosis (osteopenia, mild osteoporosis, and severe osteoporosis), and total cholesterol level data were collected from the charts. BMD was measured using dual-energy x-ray absorptiometry (DEXA). DEXA values were reported by comparison to age and sex reference groups with $t$ scores (standard deviation or percentage above or below values for young normal subjects) and $\mathrm{z}$ scores (standard deviations or percentage above or below age-matched controls). We used World Health Organization definitions, $t$ score better than -1.0 as normal, between -1.0 and -2.5 as osteopenia, less than -2.5 as osteoporosis, and less than -2.5 in presence of an osteoporotic fracture as severe osteoporosis.

The average age \pm standard deviation of the patients was $63 \pm 13$. All were postmenopausal women, and none were on cholesterol-reducing medications. Patients were classified into groups as presented in Table 1 . There were 39 subjects with osteopenia/osteoporosis and three subjects with normal BMD. Twenty-three of 39 subjects in the osteopenia/osteoporosis group (59\%) had high cholesterol levels $(>5.2 \mathrm{mmol} / \mathrm{L})$, whereas one of three in the normal BMD had high cholesterol level (33\%). This difference was not statistically significant $(P=.56$; odds ratio $=2.0,95 \%$ confidence interval $=0.2-34.5)$. Due to small sample size, we did not have the power to detect the relationship.

In this pilot study, it was observed that subjects with osteopenia or osteoporosis at lumbar spine and hip were more likely to have elevated cholesterol. This needs to be confirmed with a larger study. If it is proven, aggressive control of elevated cholesterol in addition to the existing 
therapies may help to reduce the morbidity and mortality associated with osteoporosis.

Kannayiram Alagiakrishnan, $M D, F R C P(C), A B I M$ Division of Geriatric Medicine

Laurie E. Mereu, $M D, F R C P(C)$ Division of Endocrinology

Ross T. Tsuyuki, PharmD Division of Cardiology

Michal Kalisiak, $M D$ Department of Medicine

Anne Sclater, $M S c, M D, F R C P(C)$ Division of Geriatric Medicine

Marilou Hervas-Malo, MSc Epicore Center University of Alberta Edmonton, Canada

\section{REFERENCES}

1. Yamauchi M, Sugimoto T, Yamaguchi T et al. Plasma leptin concentrations are associated with bone mineral density and the presence of vertebral fractures in post menopausal women. Clin Endocrinol (Oxford) 2001;55:341-347.

2. Yamaguchi T, Sugimoto T, Yano S et al. Plasma lipids and osteoporosis in post menopausal women. Endocr J 2002;49:211-217.

3. Mundy G, Garrett R, Harris S et al. Stimulation of bone formation in vitro and in rodents by statins. Science 1999;286:1946-1949.

4. Wang PS, Solomon DH, Mogun H et al. HMG-CoA reductase inhibitors and the risk of hip fractures in elderly patients. JAMA 2000;283:3211-3216.

5. Chan KA, Andrade SE, Boles $M$ et al. Inhibitors of hydroxymethylglutarylcoenzyme A reductase and risk of fracture among older women. Lancet 2000;355:2185-2188.

6. Bjarnason NH, Riis BJ, Christiansen C. The effect of fluvastatin on parameters of bone remodeling. Osteoporos Int 2001;12:380-384.

7. Chung YS, Lee MD, Lee SK et al. HMG-CoA reductase inhibitors increase BMD in type 2 diabetes mellitus patients. J Clin Endocrinol Metab 2000;85:1137-1142.
8. Reid IR, Hague W, Emberson J et al. Effect of pravastatin on frequency of fracture in the Lipid study: Secondary analysis of a randomized controlled trial. Lancet 2001;357:509-512.

9. Bergstrom JD, Bostedor RG, Masarachia PJ et al. Alendronate is a specific nana molar inhibitor of farnesyl diphosphate synthase. Arch Biochem Biophys 2000;373:231-241.

10. Pasco JA, Kotowicz MA, Henry MJ et al. Statin use, bone mineral density, and fracture risk: Geelong osteoporosis study. Arch Intern Med 2002;162:537-540.

\section{DOES QUESTION COMPREHENSION LIMIT THE UTILITY OF THE GERIATRIC DEPRESSION SCALE IN OLDER AFRICAN AMERICANS?}

To the Editor: The Geriatric Depression Scale (GDS) was originally proposed more than 2 decades ago to rapidly screen for depression in older adults, ${ }^{1}$ and later modified from a 30 -item test ${ }^{2}$ to a 15 -item Geriatric Depression Scale Short Form (GDS-S). ${ }^{3}$ This version has been validated and is a widely used screening tool for depression in older patients, but the utility of the GDS-S in identifying depression may be compromised when cultural, educational, or cognitive factors limit the patient's understanding of the questions. Although the GDS-S appears at first to be an objective test with straightforward yes/no answers, in clinical practice, patients often answer in an unclear fashion or ask for clarification that makes the simple coding of yes/ no more difficult. We therefore examined which of the GDS-S questions posed the most difficulty for our patients.

Fifty consecutive African-American patients were evaluated with the GDS-S given verbally by a single trained interviewer (LS) as part of routine care in the Geriatric Medicine Clinic of Grady Hospital, a large urban public hospital in Atlanta, Georgia. Information was collected on the independent variables of age, educational attainment, and Mini-Mental State Examination (MMSE) score. A question was coded as "not understood" if a patient asked for clarification or appeared confused and was still unable to answer the question after it was repeated. Aside from

Table 1. Percentage of Patients Unable to Answer Components of the Geriatric Depression Scale Short Form

Question

$\%$ Not Understood

1 Are you basically satisfied with your life?

2 Have you dropped many of your activities and interests?

3 Do you feel that your life is empty?

4 Do you often get bored?

5 Are you in good spirits most of the time?

6 Are you afraid that something bad is going to happen to you?

7 Do you feel happy most of the time?

8 Do you often feel helpless?

9 Do you prefer staying at home to going out and doing new things?

10 Do you feel you have more problems with your memory than most people?

11 Do you think it is wonderful to be alive now? 
repeating the question, no additional clarification or advice on answering the question was offered. Linear regression analysis was performed to examine the relationship between number of questions not understood and the independent variables.

The patients had a mean age of 79.5 (range $=60-96$ ). Mean educational attainment was 7.3 years (range $=1-18$ years). Mean MMSE score was 22.1 (range =13-30). Mean GDS-S score was 4.0 (range $=0-13$ ). On average, each patient did not understand one question (range 0-5), and four questions were identified that more than $10 \%$ of patients did not understand (Table 1). Linear regression analysis demonstrated an association between number of questions not understood and age $(P=.008)$, as well as MMSE score $(P=.02)$. There was no association between number of questions not understood and educational attainment.

This study demonstrates that lack of understanding of some questions on the GDS-S may be an underrecognized limitation of this test. Whether patients tend to answer negatively or affirmatively or be led by the interviewer when they do not understand a question on the GDS-S is not clear, but it is clear that misunderstanding of even a few questions can affect the ability of the practitioner to accurately detect depression using the GDS-S.

Cognitive impairment is only one possible reason for a patient not to understand GDS-S questions. Another possibility is that cultural factors contributed to difficulty understanding questions on the GDS-S. The meaning of concepts such as worthlessness and hopelessness may differ by culture and religiosity. One's usual activities and interests may also have cultural variability. It is not possible to comment on the extent to which culture may have influenced these results because this study occurred in a single ethnic group, but further examination of this possibility needs to be undertaken. Educational level was not significantly associated with lack of ability to understand questions on the GDS-S.

Although this is a small study from a selective population of African-American geriatric medicine clinic patients, and the reasons for inability to answer the questions on the GDS-S were not explored, these findings have several implications. First, this study reinforces the concept that the GDS-S is a screening rather than a diagnostic test. Important patient factors can affect the utility of the GDS-S in some patient populations, but the final diagnosis of depression remains a clinical judgment. In addition, this study has implications for proposed shortened versions of the GDS-S. For example, two questions of the shortened 5-Item Geriatric Depression Scale ${ }^{4}$ were not understood by more than $10 \%$ our study patients. It is likely that this study may underestimate the extent of this problem, because some persons who did not understand the questions may have simply given an answer rather than admit their confusion. The ideal screening test for depression in older African Americans remains to be clearly demonstrated, and this study points out some important concerns regarding use of the GDS-S if it is to be used clinically for depression screening in this patient popula- tion. Whether other screening tools for depression share this same problem remains to be demonstrated.

Jonathan M. Flacker, MD
Louise Spiro, MSW, LCSW
Division of Geriatric Medicine and Gerontology
Emory University School of Medicine
Atlanta, GA

Department of Social Work
Grady Health Systems
Atlanta, GA

\section{REFERENCES}

1. Brink TL, Yesavage JA, Lum O et al. Screening tests for geriatric depression. Clin Gerontol 1982;1:37-44.

2. Yesavage JA, Brink TL, Rose TL et al. Development and validation of a geriatric depression screening scale: A preliminary report. J Psychiatr Res 1983;17: 37-49.

3. Sheikh JI, Yesavage JA. Geriatric Depression Scale (GDS). Recent evidence and development of a shorter version. Clin Gerontol 1986;5:165-173.

4. Hoyl MT, Alessi CA, Harker JO et al. Development and testing of a five-item version of the Geriatric Depression Scale. J Am Geriatr Soc 1999;47:873-878.

\section{S IS HARRY S TRUMAN'S MIDDLE NAME, NOT AN INITIAL}

To the Editor: The purpose of this letter to the editor is first to congratulate Yoshikawa, Reuben, and Ouslander for their most touching tribute to Dr. Solomon. ${ }^{1}$ Another and more important reason for this letter to the editor is to congratulate them for spelling the middle name of Harry $S$ Truman correctly, without a period after "S."

$S$ in Harry S Truman, the 33rd President of the United States, is Truman's full middle name, not an initial, ${ }^{2}$ but in almost all the publications and dictionaries, $S$ was followed by a period, as if it were an initial. $S$ actually did not stand for anything, a practice not unknown among the ScotchIrish. $^{2}$

Like Truman, my middle name is $\mathrm{O}$, which is also not an initial. $\mathrm{O}$ is a phonetic translation of my middle name in Chinese, but it became an initial on my naturalization paper, so I have to live with this error for the rest of my life.

\section{REFERENCES}

1. Yoshikawa TT, Reuben DB, Ouslander JG. Biographical sketch of David H. Solomon, MD. J Am Geriatr Soc 2003;51:S330-S332.

2. McCullough D. Truman. New York: Simon \& Schuster, 1992.

Tsung O. Cheng, MD George Washington University Washington, DC 